Manejo Contable en la empresa

\title{
Manejo Contable en la empresa
}

\section{Accounting Management in the company}

\section{Gestão de Contabilidade na empresa}

\author{
Luz M. Cifuentes-Quiñonez ${ }^{\text {I }}$ \\ luzmcifuentes@hotmail.com \\ Iván O. Endara-Arguello II \\ ivan.endara@utelvt.edu.ec \\ Pedro. E. Reyes-Vélez III \\ pereyesvelez@hotmail.com \\ Limber L. Rivas-Cedeño IV \\ limberrivasc@gmail.com
}

Recibido: 28 de septiembre de 2017 * Corregido: 25 de noviembre de 2017 * Aceptado: 18 de diciembre de 2017

I. Magister en Docencia Mención Gestión en Desarrollo del Currículo, Magister en Administración de Empresas, Licenciado en Contabilidad y Auditoría, Doctora en Contabilidad y Auditoría, Técnica en Comunicación Radiofónica Para el Desarrollo, Docente en la Universidad Técnica Luis Vargas Torres De Esmeraldas, Esmeraldas, Ecuador.

II. Magister en Gestión Empresarial, Ingeniero de Sistemas y Computación, Docente en la Universidad Técnica Luis Vargas Torres De Esmeraldas, Esmeraldas, Ecuador

III. Magister en Gerencia de Proyectos Educativos y Sociales, Magister en Gestión Ambiental, Magister en Administración de Empresas Mención Dirección Financiera, Ingeniero Industrial, Docente en la Universidad Laica "Eloy Alfaro" de Manabí, Manta, Ecuador.

IV. Magister en Docencia Mención Gestión en Desarrollo del Currículo, Profesor de Segunda Enseñanza en la Especialidad de Supervisión y Administración Educativa, Licenciado en Ciencias de la Educación en la Especialidad de Supervisión y Administración Educativa, Abogado de Los Juzgados y Tribunales de la Republica, Docente en la Universidad Laica "Eloy Alfaro" de Manabí, Manta, Ecuador. 


\section{Resumen}

La presente investigación contempla diversos aspectos generales acerca de la contabilidad en una empresa, con particulares variaciones que responden más que todo al origen del capital y a la clase de la actividad económica a la que se dedica dicha entidad de trabajo. El surgimiento de diversos e innovadores negocios, no están exentos de ser objeto de un manejo contable de sus recursos, se hace necesario aun cuando dentro de la organización no se cuente con un equipo contable o un profesional dedicado a la materia, que todo nicho financiero que procure un crecimiento económico per se debe llevar una sana contabilidad. Básicamente, es raíz de la ausencia de una información contable básica que nace la iniciativa de este trabajo, con el que claramente no se pretende dilucidar o abarcar amplia y profundamente lo que concierne a toda la técnica contable, sino más bien tratar temas básicos, generales, que muy bien pudieran servir a cualquier persona de pilar para iniciar sanamente un negocio o emprendimiento. De igual manera, se pretende dar un enfoque documental-descriptivo del mismo, para ello se hará uso de una revisión bibliográfica en libros, revistas, periódicos, memorias, anuarios, blogs, artículos científicos, publicaciones, sean de fuentes físicas o digitales, con la finalidad de aportar herramientas fundamentales al interesado para se instruya respecto a conceptos básicos sobre la contabilidad en una empresa.

Palabras clave: contabilidad; negocios; emprendimiento; finanzas; operaciones.

\section{Abstract}

The present investigation contemplates diverse general aspects about the accounting in a company, with particular variations that respond more than everything to the origin of the capital and to the class of the economic activity to which this work entity is dedicated. The emergence of diverse and innovative businesses, are not exempt from being subject to accounting management of their resources, it is necessary even when within the organization there is no accounting team or a professional dedicated to the matter, that any financial niche that seeks economic growth per se should carry a healthy accounting. Basically, it is the root of the absence of a basic accounting information that gives rise to the initiative of this work, with which it is clearly not intended to elucidate or comprehensively and comprehensively cover all the accounting technique, but rather to deal with basic, general issues, which could very well serve any pillar person to start a business or venture healthy. Similarly, it is intended to give a documentary-descriptive approach to it, for this purpose it 
will make use of a bibliographic review in books, magazines, newspapers, memories, yearbooks, blogs, scientific articles, publications, whether from physical or digital sources, with the purpose of providing fundamental tools to the interested to be instructed regarding basic concepts about accounting in a company.

Keywords: accounting; business; entrepreneurship; finance; operations

\section{Resumo}

A presente investigação contempla diversos aspectos gerais da contabilidade em uma empresa, com variações particulares que respondem mais do que tudo à origem do capital e à classe da atividade econômica a que esta entidade de trabalho é dedicada. O surgimento de negócios diversos e inovadores, não estão isentos de estar sujeito à administração contábil de seus recursos, é necessário mesmo quando dentro da organização não há equipe de contabilidade ou um profissional dedicado ao assunto, que qualquer nicho financeiro que busca o crescimento econômico per se deve levar uma contabilidade saudável. Basicamente, é a raiz da ausência de uma informação contábil básica que dá origem à iniciativa deste trabalho, com a qual claramente não se destina a elucidar ou abranger de forma abrangente e abrangente toda a técnica contábil, mas sim lidar com questões básicas e gerais , o que poderia muito bem servir qualquer pessoa do pilar para iniciar um negócio ou se aventurar saudável. Da mesma forma, pretende-se dar uma abordagem documental-descritiva para isso, utilizará uma revisão bibliográfica em livros, revistas, jornais, memórias, anuários, blogs, artigos científicos, publicações, seja de fontes físicas ou digitais, com com o objetivo de fornecer ferramentas fundamentais aos interessados para serem instruídos sobre conceitos básicos sobre contabilidade em uma empresa.

Palavras chave: contabilidade; negócios; empreendedorismo; finanças; operações.

\section{Introducción}

Si bien es cierto que en la actualidad existen diversas alternativas de tipo tecnológico (software) que bien sirven, facilitan y complementan la contabilidad de empresas, sean pequeñas, medianas o grandes, no es menos cierto que no deja de ser imprescindible el capital humano capacitado que saque el mayor provecho a dichas herramientas tecnológicas, pues son quienes darán la interpretación correcta del cúmulo de información que se recaba, organiza y registra en todo manejo contable. 
En una empresa, la contabilidad sirve para llevar el control sobre todas las cuentas y operaciones diarias, tales como las de compra, venta, gastos, inversiones, entre otras. La labor de quien maneje la contabilidad se fundamenta en la organización de los documentos y, tanto registrar como reportar las actividades que se realicen con el dinero ya sea movimientos tangibles o intangibles.

Un sistema de información contable comprende los métodos, procedimientos y recursos utilizados por una entidad para llevar un control de las actividades financieras y resumirlas en forma útil para la toma de decisiones. Un sistema de información bien diseñado ofrece control, compatibilidad, flexibilidad y una relación aceptable de costo/beneficio, de allí la importancia de la contabilidad, la cual es hoy en día bastamente reconocida y aceptada por cualquier ente privado o gubernamental, puesto que están plenamente convencidos que para obtener una mayor productividad y aprovechamiento de su patrimonio, así como para cualquier información de carácter legal, son imprescindibles los servicios prestados por la contabilidad.

Así mismo, las operaciones son para analizarlas, clasificarlas, resumirlas y finalmente ponerlas en un estado financiero o balance que debe contener toda la información veraz y realidad financiera de la empresa.

\section{Materiales y métodos}

Partiendo del hecho de saber que el método científico es uno, hay que recordar que existen diversas formas de identificar la aplicación o práctica de la investigación. De esta manera se compre entonces que igualmente hay diferentes formas de clasificar la investigación.

Según la literatura consultada y el enfoque que se pretende con este trabajo, se puede definir la presente investigación como una de tipo Documental-Descriptiva. En específico se dice que es de tipo documental puesto que, según (Alfonso, 1994), la investigación documental es un procedimiento científico, un proceso sistemático de indagación, recolección, organización, análisis e interpretación de información o datos en torno a un determinado tema. Al igual que otros tipos de investigación, éste es conducente a la construcción de conocimientos. Aunado a esto, se cita en Grajales (s.f.) "la investigación documental es aquella que se realiza a través de la consulta de documentos (libros, revistas, periódicos, memorias, anuarios, registros, códices, constituciones, etc.)". Así, el mismo autor refiere que: 
Los estudios descriptivos buscan desarrollar una imagen o fiel representación (descripción) del fenómeno estudiado a partir de sus características. Describir en este caso es sinónimo de medir. Miden variables o conceptos con el fin de especificar las propiedades importantes de comunidades, personas, grupos o fenómeno bajo análisis.

\section{Resultados}

La contabilidad es una técnica que se ocupa de registrar, clasificar y resumir las operaciones mercantiles de un negocio con el fin de interpretar sus resultados, para que los gerentes a través de ella puedan orientarse sobre el curso que siguen sus actividades comerciales; permitiendo así conocer la estabilidad, la solvencia y la capacidad financiera de la empresa. (Josar, s.f.)

El manejo contable de un negocio permite conocer las necesidades a las que se debe enfrentar sus representantes y los recursos con los que cuenta para ello. De hecho, es entendido que, si no se es precavido con la contabilidad, se corre el riesgo de agotar los ingresos y percatarse de ello tardíamente o a desconocer las acreencias de la empresa.

\section{Clasificación}

Según Díaz (2006) la contabilidad puede clasificarse básicamente de dos maneras:

\section{A) Según el origen del capital:}

Privada o particular, si se ocupa del registro de transacciones y la preparación de estados financieros de empresas particulares.

Oficial o gubernamental, si se ocupa del registro de información del Estado o de las instituciones y los diferentes organismos estatales.

\section{B) Según la clase de actividad:}

La contabilidad también puede clasificarse de acuerdo con la actividad económica desarrollada por la empresa: 
Comercial, si registra las operaciones de empresas o negocios dedicados a la compra y venta de bienes o mercancías, sin ningún proceso adicional de trasformación de éstas.

Industrial o de costos, si registra las operaciones de empresas dedicadas a la fabricación o elaboración de productos mediante la trasformación de materias primas, permitiendo determinar los costos unitarios de producción o de explotación.

Servicios, si registra las operaciones de empresas dedicadas a la venta y prestación de servicios, o a la venta de capacidad profesional. En este grupo se tienen: entidades bancarias, instituciones educativas, hospitales, clínicas, talleres de servicio, empresas de turismo, servicio de trasporte, empresas de asesoría profesional, etcétera.

Agropecuaria, aquella que registra las operaciones de empresas dedicadas a las actividades de agricultura o ganadería.

\section{Objetivo}

En la contabilidad el objetivo más importante es proporcionarles información financiera de la empresa a las personas y entidades interesadas en conocer los resultados operacionales y la verdadera situación económica de la misma, con el fin de que se tomen decisiones.

Teniendo claro lo anterior, ahora es necesario pasar a conocer la ecuación contable que se conoce como la partida doble, planteada así:

\section{Activo - Pasivo $=$ Patrimonio}

Entendiéndose en esta ecuación que el activo, son los bienes y derechos de la empresa; el pasivo, son las obligaciones y compromisos que contrae la empresa, y el patrimonio, es el capital con el que cuenta la organización. (Reyes, 2013)

En “Tips básicos para llevar la contabilidad...” (2017) se definen los siguientes conceptos:

Balance General: es un resumen que refleja el panorama actual de una empresa. Este sirve para guiar a los dueños del negocio en la toma de decisiones financieras. Básicamente es un resumen de todo lo que tiene la empresa, lo que debe y lo que realmente le pertenece al propietario. 
Estado de Resultados: en este documento se registran los datos de un momento en específico de la empresa para que nos muestre el estado de pérdidas o ganancias. Sus componentes son:

a) Ingresos: los que se obtuvieron durante el periodo contable que se está reportando. Ejemplo: ingresos por ventas, ingresos financieros u otros ingresos.

b) Costos: es el gasto económico que representa la fabricación de un producto o la prestación de un servicio. Al determinar el costo de producción, se puede establecer el precio de venta al público que es la suma del costo más el beneficio.

c) Gastos: siempre implica una salida de dinero. Pueden ser los gastos fijos como, por ejemplo, el pago del alquiler, la nómina o los servicios o gastos variables por alguna emergencia.

\section{¿Cómo se lleva la contabilidad?}

La clave es tener disciplina y crear el hábito de archivar todos los documentos que sean necesarios, para ello, cumpliendo los siguientes cuatro pasos se puede comprender cómo debe ser la organización para llevar una buena gestión contable sobre los movimientos de su empresa y las operaciones financieras.

$1^{\circ}$. Escoja un programa de facturación: el control de los ingresos y gastos es lo principal. Use preferiblemente la tecnología, es decir, un software de los que hoy en día es posible acceder gratuitamente (esto en caso de que contar con muy pocos recursos económicos en un emprendimiento) que tenga plantillas para facturas y que las archive para que así posteriormente se pueda analizar la información de la manera más sencilla posible, y además poder hacer proyecciones sobre el negocio.

$2^{\circ}$. Lleve un registro de sus gastos e ingresos: en ambos casos organícelos por categorías. Escriba o haga una copia de los recibos que entregue a sus clientes, y en el caso de los gastos, divídalos en fijos (créditos, servicios, nómina, etcétera) y variables (emergencias, o gastos esporádicos)

$3^{\circ}$. Lleve un registro de los impuestos: la primera tarea es que averigüe cuáles son los impuestos que tiene que pagar. Haga un calendario para que anote las fechas importantes del año en los que debe tener listos documentos y debe cumplir con esta obligación. 
$4^{\circ}$. Ahorre tiempo y dinero: elija una vez al mes o cada quince días un día para organizar los documentos y archivar las operaciones contables para el momento en que necesite hacer el balance general o el pago de impuesto. Recuerde que si tiene todo en orden puede encontrar beneficios tributarios.

\section{Conclusiones}

La contabilidad en la empresa es un proceso necesario que sirve para conocer los estados patrimoniales de la misma. Es prácticamente imposible tener un manejo razonable de una organización sin conocer con exactitud sus números y circunstancias patrimoniales, sus relaciones entre activos y activos. Esta circunstancia es cierta tanto para una gran empresa como para un micro emprendimiento, aunque es cierto que en el segundo caso puede existir un registro muy rudimentario. A la hora de tomar decisiones de tipo económico es enormemente importante llevar un buen seguimiento que dé cuenta de la situación en la que una organización o una persona se encuentran. (Importancia, 2002-2015)

Por otra parte, de entenderse que una empresa tiene como finalidad la obtención de una ganancia o rentabilidad, para ello, por ejemplo, debe considerar los precios que existen en el mercado de los bienes y servicios de su competencia, e intentar producirlos con un menor costo. La diferencia entre estos precios y los costos será la denominada rentabilidad de la empresa.

Ahora bien, si bien es cierto que es fácil entender lo anteriormente expuesto, no hay que dejar de tener claro que para que la contabilidad se constituya como herramienta fundamental en una empresa, debe llevar adelante su objetivo primordial, que no es más que el seguimiento exhaustivo de esos valores (precio, costo) que sólo se puede controlar mediante un registro pormenorizado de todas las transacciones y decisiones que se tomen, y que impliquen la salida y la entrada de dinero.

Más delante en el tiempo es muy probable que el sistema contable en vigencia se llegue a modificar. De hecho, lo que pudiera llevar evaluar nuevas formas de registro contable, más precisos, son los cambios existentes en la sociedad, y en ese sentido la contabilidad en la empresa seguramente va a mejorar.

En definitiva, se puede asegurar que llevar la Contabilidad de forma personal, bajo los principios y técnicas ya someramente expuestas o dejarla en manos de un experto permitirá (Heredia, s.f.) 
1. Tener un control de todas las ventas del día para conocer los ingresos diarios.

2. Llevar la cuenta de todos los gastos, como compras a proveedores, rentas, consumo de servicios, etcétera.

3. Hacer un balance general entre ingresos y egresos, llevando registro de las facturas o tickets emitidos, para compararlos fácilmente si fuera necesario.

4. Administrar el inventario de productos e insumos, a fines de saber cuántas unidades quedan de cada cosa.

5. Controlar los servicios que estamos utilizando, como los recibos del agua, de la luz, del teléfono, entre otros.

\section{Referencias Bibliográficas}

Tips básicos para llevar la contabilidad de su negocio sin tener un contador. (2017). Recuperado el 29 de noviembre de 2017, de http://www.finanzaspersonales.co/trabajo-yeducacion/articulo/contabilidad-como-organizar-la-cuentas-en-mi-negocio/72914

Alfonso, I. (1994). Técnicas de investigación bibliográfica. Caracas: Contexto Ediciones.

Díaz, H. (2006). Contabilidad General. Enfoque práctico con aplicaciones informáticas (2a Ed. ed.). (M. F. Castillo, Ed.) Naucalpan de Juárez: Pearson Educación de México, S.A. de C.V.

Grajales, T. (s.f.). http://tgrajales.net. Recuperado el 05 de diciembre de 2017, de http://tgrajales.net/investipos.pdf

Heredia, F. (s.f.). Mi Propio Jefe. Recuperado el 29 de noviembre de 2017, de https://mipropiojefe.com/5-razones-para-llevar-la-contabilidad-de-tu-empresa/

Importancia. (2002-2015). Importancia. Recuperado el 02 de diciembre de 2017, de Importancia: https://www.importancia.org/contabilidad-en-la-empresa.php 
Manejo Contable en la empresa

Josar, C. (s.f.). Asociación Española de Contabilidad y Administración de Empresas. Recuperado el 05 de diciembre de 2017, de http://aeca.es/old/buscador/infoaeca/articulosespecializados/pdf/auditoria/pdfcontabilidad/2.pdf

Reyes, J. (2013). SoyConta. Recuperado el 02 de diciembre de 2017, de http://www.soyconta.mx/contabilidad-para-no-contadores/ 